\title{
DIAGRAMA MORFOLÓGICO PARTE I: INSTRUMENTO DE ANÁLISE E PROJETO AMBIENTAL COM USO DE LUZ NATURAL
}

\author{
AMORIM, Cláudia Naves David
}

\section{RESUMO}

O projeto de arquitetura deve, por definição, encontrar um "compromisso" entre exigências de diversos tipos, dentre as quais os requisitos funcionais, estéticos, ambientais e econômicos que a obra arquitetônica deve resolver de maneira satisfatória. Considerando as questões ambientais, hoje prementes no contexto mundial da arquitetura, pode-se dizer que a luz natural e todas as suas implicações no projeto têm uma importante dimensão, do ponto de vista ambiental, funcional e qualitativo da arquitetura. Incorporar a luz natural no processo de projeto de forma coerente, otimizando seus benefícios e minimizando impactos negativos, tornase crucial. O presente artigo apresenta o DiagramaMorfológico, instrumento síntese de parâmetros fundamentais para o projeto arquitetônico relacionados à luz natural, e que pode ser utilizado no processo de projeto ou para descrição e avaliação de edificações existentes do ponto de vista ambiental, com ênfase nos aspectos de conforto ambiental e eficiência energética através da luz natural. Descreve-se o instrumento e sua aplicação, evidenciando as vantagens de seu uso na formação e desenvolvimento do senso crítico dos projetistas e na construção de repertório arquitetônico de referência, fundamental para o projetista e a qualidade de seus projetos.

Palavras chave: Diagrama morfológico; iluminação natural; projeto ambiental

\section{ABSTRACT \\ The architectural design must find a "compromise" between many requirements, as functional, aesthetics, environmental and economic ones. Considering environmental questions, very pressing in the global context, one can say that daylighting and all its}

consequences in the design have an important dimension from the environmental, functional and qualitative point of fiew in the architectural design. To include daylighting in the design process in a consistent way, optimizing its benefits and minimizing negative impacts becomes crucial. This article presents the "Morphological Diagram", a synthesis tool of fundamental parameters to the architectural design related to daylighting, that can be used in the design process or in the description and evaluation of existent buildings from the environmental point of view, emphasising daylighting. The tool and application are described, making evident the advantages of it's use in development of critical sense of designers and in the forming of an architectural reference repertory, basic for the designer and the quality of his projects.

Key words: Morphological Diagram; daylighting; environmental design

\section{INTRODUÇÃO}

As crescentes necessidades surgidas nos últimos anos, relacionadas aos aspectos ambientais $^{a}$ do espaço construído, vêm abrindo caminhos cada vez mais direcionados ao uso dos recursos naturais, como radiação solar, ventilação natural, etc. A luz natural, proveniente da radiação solar, utilizada de forma direta ou difusa, é um importante quesito para atingir maior qualidade ambiental (conforto ambiental e eficiência energética, dentre outros aspectos $^{b}$ ) e a conseqüente sustentabilidade nos espaços construídos.

No entanto, várias pesquisas (AMORIM, 2001; GARROCHO, 2007; SILVA, 2007) evidenciam a dificuldade dos projetistas, principalmente no contexto brasileiro, em atender de maneira consciente aos requisitos de uma boa iluminação natural, equilibrando a entrada de luz e calor, mantendo as demais preocupações de um 
projeto arquitetônico, ligadas aos requisitos funcionais, estéticos, construtivos e econômicos.

Baker et al (1993) e IEA (2000) mencionam algumas maneiras de persuadir os projetistas $^{c} \mathrm{e}$ incrementar o uso consciente da luz natural: evidenciar as possibilidades existentes através de estudos de caso exemplares, fornecer informações e análises descrevendo os aspectos relevantes dos estudos de caso e, por fim, disponibilizar aos projetistas instrumentos para auxílio no projeto ou análise de projetos.

\section{O PROCESSO PROJETUAL: ANÁLISE E SÍNTESE}

O projeto de arquitetura, apesar de ser um processo técnico-criativo, onde entram em jogo diversas questões de ordem muito diversificada, "não equivale à resolução de uma equação matemática, na qual épossível individuar uma seqüência definida de operações que levam a um resultado final único e incontestável; enquanto processo de síntese e de escolha, o processo permite um grande número de soluções possíveis, que serão mais ou menos adequadas..." (ROGORA, 1997, p. 65). Isto implica, necessariamente, em um processo de análise (dos condicionantes, do programa de necessidades, etc.) e síntese, que poderá apresentar diferentes soluções.

O processo de projeto arquitetônico tradicional, pode-se afirmar, apresenta uma série de incertezas e fases conduzidas quase que somente pela intuição do projetista; além disso, normalmente, em um projeto tradicional, "há uma ênfase ao desenho de uma só pessoa, geralmente o titular do escritório" (BAKER et al, op.cit., p.11.1). O esboço inicial do projeto, crítico para o uso da luz natural e dos aspectos ambientais a ela relacionados é quase sempre realizado em período de tempo relativamente curto, segundo critérios intuitivos, visuais e estéticos - neste sentido, a forma, massa, espaço e volume entram como elementos da composição. Isto gera quase sempre uma falta de oportunidade para que especialistas possam contribuir nas fases iniciais do processo projetual (BAKER et al, op.cit., p. 11.1). Aspectos mais específicos, que deveriam entrar na fase inicial, não são examinados nesta fase. Relacionando com um exemplo ligado ao uso da luz natural, por exemplo, questões relativas à implantação e forma da edificação, que condicionam inteiramente a quantidade e qualidade da luz natural, são geralmente decididas em função de outros fatores.

Por outro lado, mesmo um projeto muito bem resolvido sobvários aspectosé passível de críticas e/ou melhorias, que podemos chamar de "processo de otimização". Este processo, a nosso ver, é infinito e indefinido, conforme o olhar do observador ou conforme o parâmetro de avaliação. Esta situação teoricamente poderia levar a um eterno "descontentamento" com o produto final; no entanto, de qualquer maneira é necessário ter parâmetros, ainda que estes sejam parciais e variáveis conforme a evolução da tecnologia e do nível de exigência, do contexto climático, etc. ${ }^{\mathrm{d}}$

\section{PROJETO DE ARQUITETURA: REPERTÓRIO E INSTRUMENTOS}

Os projetistas (principalmente arquitetos) utilizam para o projeto, de maneira geral, referências baseadas em um repertório já conhecido, visto ou visitado pessoalmente ou apreendido da bibliografia especializada (livros, revistas e periódicos de arquitetura). Em geral, trabalha-se com idéias de projeto provindas de um repertório de formas de edifícios visitados ou vistos - alteradas e adaptadas segundo as exigências do projeto específico a ser executado.

Neste sentido, alguns autores têm realizado trabalhos buscando reunir repertório de arquitetura exemplar no uso da iluminação natural e da adequação ao contexto climático (LAM, 1986; BAKER, 1993; TORRICELLI et al,1996; FONTONOYONT, 1999; AMORIM, 2001), ou sistematizando o processo de organização deste repertório projetual (BAKER, 1993; ROGORA, 1998; OLIVEIRA, 1998). Lam (1986), após teorizar sobre o uso da luz direta do sol como elemento de valorização arquitetônica e eficiência energética, apresenta vários projetos de edifícios que 
ilustram os conceitos elencados. Baker (1993) reúne em um compêndio que se tornou um clássico da área, informações teóricas sobre o uso da luz natural e alguns projetos que ilustram o bom uso desta. Torricelli et al (1996) valem-se deste mesmo procedimento, apresentando projetos que “...colocam em evidência o aspecto criativo e a pesquisa arquitetônica mais original ligada ao controle da luz natural, levando em consideração o fato de que toda arquitetura deve ser avaliada em relação ao seu contexto climático e ambiental."e Fontoyonont (1999), dentro da estratégia de pesquisa da Task 21 da International Energy Agency, apresenta uma coletânea de projetos arquitetônicos de várias épocas, desde a antiguidade até projetos contemporâneos, com dados e informações coletadas segundo procedimentos específicos. O resultado desta coletânea é um compêndio que analisa os edifícios do ponto de vista da luz natural, despertando o olhar do projetista para procedimentos, estratégias e detalhes significativos que podem ser utilizados em outros projetos. Também Amorim (2001) ao analisar estratégias adequadas para a luz natural em climas tropicais em edifícios comerciais, apresenta alguns projetos arquitetônicos exemplares, que utilizam estas estratégias. É importante frisar que o uso deste repertório catalogado também deve considerar o contexto climático local, analisando e adaptando as soluções propostas.

O trabalho de Rogora (1996) baseiase na sistematização do que o autor denomina "Gramática da Luz", baseandose em aspectos fisiológicos, biológicos e psicológicos da relação da luz natural com o projeto arquitetônico. Oliveira (1998), por suavez, identifica esistematiza oschamados efeitos lumínicos e propõe-se a corroborar com a criação de uma "linguagem da luz", que teria o objetivo de auxiliar o projetista no decorrer do processo de projeto. Ambos autores servem-se também da análise de projetos existentes para evidenciar seus pontos positivos e testar os métodos de análise propostos.

É certo que os projetistas (principalmente arquitetos, mas também luminotécnicos) têm interesse, de maneira geral, principalmente nos aspectos estéticos da luz. O momento atual brasileiro, no entanto, visto a carência de normas e incentivos para projetos conscientes do ponto de vista ambiental ${ }^{\dagger}$, é de construção e disseminação de conhecimentos através de instrumentos que levem a projetos do espaço construído mais sustentáveis e de maior qualidade ambiental (conforto e eficiência energética, principalmente), facilitando a aplicação deste conhecimento à comunidade de projetistas.

Por este motivo, a ênfase do presente trabalho é unir em um instrumento os aspectos relacionados ao uso da luz natural no projeto arquitetônico e às conseqüências ambientais e energéticas diretamente ligadas a cada solução projetual. Pretendese, desta maneira, realizar um recorte do problema, que permite limitar o número de variáveis e facilitar seu aprendizado, relacionamento e a disseminação dos conceitos de qualidade ambiental e sustentabilidade (especialmente ligadas a eficiência energética e conforto ambiental) ligados à luz natural.

\section{O DIAGRAMA MORFOLÓGICO COMO INSTRUMENTO PROJETUAL E DE ANÁLISE}

Das diversas maneiras para disseminar o uso eficiente da luz natural nos espaços construídos, propostas por Baker et al. (1993), uma delas propõe mostrar as possibilidades arquitetônicas através de estudos de caso exemplares, fornecendo análises e informações que descrevem seus aspectos relevantes. Os próprios autores desenvolveram o chamado Morphological Box, que pode ser um instrumento bastante útil para esta análise e catalogação de projetos arquitetônicos. Visto que a teoria da composição arquitetônica desenvolveuse como um instrumento de projeto cumulativo, o método, segundo os autores, pode ser chamado de "método tipológico", com um repertório armazenado de formas e tipos, estruturados em uma gramática arquitetônica, que permite que estes 
modelos sejam adaptados a programas específicos.

A partir deste conceito, gerou-se novo instrumento, adaptado do precedente, denominado então "Diagrama Morfológico", que é um modelo para análise de projetos, que pode ser utilizado também durante o processo projetual. Este instrumento adapta o conceito original acrescentando categorias com base nas especificidades do contexto climático e construtivo brasileiro, além de ampliar a análise, originalmente restrita à luz natural, a outros quesitos ambientais, como ventilação natural, integração com a luz artificial e controles, visando uma maior aplicabilidade do instrumento para uma análise do ponto de vista ambiental, (principalmente conforto ambiental e eficiência energética) do projeto. Esta ampliação baseia-se no fato de que o espaço construído, por definição, deve equacionar os problemas térmicos, de iluminação e outros, através de sua forma, invólucro e aberturas, e portanto, as decisões de projeto envolverão estes conceitos.

O Diagrama pode ser utilizado para leitura e análise de um projeto existente, ou como auxiliar no processo de projeto. Neste exercício, pode-se preencher o diagrama com as características do edifício identificado como sendo um bom exemplo de projeto com a iluminação natural, ou pode-se utilizá-lo para identificar os pontos do projeto que necessitam de otimização. Este exercício tem como objetivo sensibilizar o projetista para identificar certos aspectos cruciais de projeto, criar repertório projetual e aguçar seu senso crítico para a percepção das conseqüências das escolhas projetuais (impactos das decisões de projeto em todos os aspectos ambientais, principalmente de conforto ambiental e eficiência energética).

O Diagrama Morfológico é utilizado para apresentar uma seleção de sistemas e estratégias efetivos para a luz natural em edifícios. Neste diagrama, através da combinação de "Parâmetros" e "Variáveis" pode-se representar uma série de soluções de projeto. Configura-se então uma "Gramática tipológica arquitetônica"g, que pode gerar elementos do conjunto arquitetônico específico daquele projeto.

O uso do Diagrama poderá tornar-se um instrumento efetivo para a criação de um repertório de soluções adequadas de projeto e para a sensibilização na leitura de projetos com especial atenção ao uso da luz natural e aos aspectos ambientais relacionados a conforto ambiental e eficiência energética.

O Diagrama apresenta-se dividido em três Níveis (Espaço Urbano, Edifício e Ambiente Interno, que são considerados suficientes para se caracterizar o edifício e suas relações com o entorno ${ }^{\mathrm{h}}$; cada Nível apresenta diversos Parâmetros, cada um deles podendo ser representado por algumas Variáveis. O "ambiente" ou "espaço" (externo ou interno) é visto como um conjunto de planos formando o piso, as paredes com aberturas, o teto, etc. A combinação de vários planos produz muitos "ambientes" diferentes; os planos que compõem este ambiente são os "PARÂMETROS" do DIAGRAMA MORFOLÓGICO, e as várias possibilidades de configuração de pisos, paredes, janelas são suas "VARIÁVEIS". O Quadro 1 apresenta os Níveis, Parâmetros e Variáveis do Diagrama Morfológico, descritos detalhadamente em seguida para melhor compreensão e utilização. Cada uma das Variáveis propostas nos Parâmetros dos 3 Níveis é simbolizada com um ícone, que auxilia no processo de compreensão do significado e interpretação da mesma, e é utilizado no momento do preenchimento do Diagrama Morfológico de um determinado projeto. A seguir apresentam-se todos os Níveis, Parâmetros e Variáveis, explicando detalhadamente cada um e seus impactos no projeto, do ponto de vista da iluminação natural, conforto ambiental e eficiência energética (ver Quadro 1). 


\begin{tabular}{|c|c|c|}
\hline NIVEL & PARAMIETROS & VARIAVEIS \\
\hline $\begin{array}{l}\text { I } \\
\text { Espaço } \\
\text { urbano }\end{array}$ & $\begin{array}{l}\text { A Desenho Urbano } \\
\text { B Refletância fachadas } \\
\text { C Especularidade fachadas } \\
\text { D Ângulo máximo do sol na base do edifício }\end{array}$ & $\begin{array}{l}\text { A1, A2, A3, A4, A5, A6, A7, A8, A9 } \\
\text { B1, B2, B3, B4 } \\
\text { C1, C2, C3, C4 } \\
\text { D1, D2, D3, D4 }\end{array}$ \\
\hline$\underset{\text { II }}{\text { Edifício }}$ & $\begin{array}{l}\text { E Forma e Planta Baixa } \\
\text { F Taxa de aberturas } \\
\text { G Distribuição de aberturas } \\
\text { H Proteções solares nas fachadas } \\
\text { I Aberturas Zenitais } \\
\text { J Mecanismos de ventilação natural }\end{array}$ & $\begin{array}{l}\mathrm{E} 1, \mathrm{E} 2, \mathrm{E} 3, \mathrm{E} 4, \mathrm{E} 5, \mathrm{E} 6 \\
\mathrm{~F} 1, \mathrm{~F} 2, \mathrm{~F} 3, \mathrm{~F} 4 \\
\mathrm{G} 1, \mathrm{G} 2, \mathrm{G} 3, \mathrm{G} 4 \\
\mathrm{H} 1, \mathrm{H} 2, \mathrm{H} 3, \mathrm{H} 4, \mathrm{H} 5, \mathrm{H} 6 \\
\mathrm{I} 1, \mathrm{I} 2, \mathrm{I} 3, \mathrm{I} 4, \mathrm{I} 5, \mathrm{I} 6 \\
\mathrm{~J} 1, \mathrm{~J} 2, \mathrm{~J} 3, \mathrm{~J} 4\end{array}$ \\
\hline $\begin{array}{c}\text { III } \\
\text { Ambiente }\end{array}$ & $\begin{array}{l}\text { K Planta Baixa } \\
\text { L Posição do coletor de luz } \\
\text { M Área do coletor de luz } \\
\text { N Forma do coletor de luz } \\
\text { O Controle da entrada de luz } \\
\text { P Controle da ventilação natural } \\
\text { Q Controle e integração da iluminação artificial }\end{array}$ & $\begin{array}{l}\mathrm{K} 1, \mathrm{~K} 2, \mathrm{~K} 3, \mathrm{~K} 4 \\
\mathrm{~L} 1, \mathrm{~L} 2, \mathrm{~L} 3, \mathrm{~L} 4, \mathrm{~L} 5, \mathrm{~L} 6 \\
\mathrm{M} 1, \mathrm{M} 2, \mathrm{M} 3, \mathrm{M} 4, \mathrm{M} 5, \mathrm{M} 6 \\
\mathrm{~N} 1, \mathrm{~N} 2, \mathrm{~N} 3, \mathrm{~N} 4, \mathrm{~N} 5, \mathrm{~N} 6 \\
\mathrm{O} 1, \mathrm{O} 2, \mathrm{O} 3, \mathrm{O} 4, \mathrm{O} 5, \mathrm{O} 6 \\
\mathrm{P} 1, \mathrm{P} 2, \mathrm{P} 3, \mathrm{P} 4, \mathrm{P} 5, \mathrm{P} 6 \\
\mathrm{Q} 1, \mathrm{Q} 2, \mathrm{Q} 3, \mathrm{Q} 4, \mathrm{Q} 5, \mathrm{Q} 6\end{array}$ \\
\hline
\end{tabular}

Quadro 1: Níveis, Parâmetros e Variáveis do Diagrama Morfológico

\section{NÍVEL I - ESPAÇO URBANO}

\section{Parâmetro A: Desenho Urbano}

Variáveis: (ver Figura 1) A1 - Pequenos quarteirões irregulares, A2 - Grandes quarteirões, A3 - Quarteirões orientados em relação ao sol, A4 - Superquadrasi, A5 - Fachadas principais orientadas para Norte/Sul, A6 - Fachadas principais orientadas para Leste/ Oeste, A7 - Fachadas principais com orientação intermediária, A8 - Blocos abertos, A9 - Torres, A10 - Torre isolada, A - 11 Outrosj.

\section{A - Desenho Urbano}

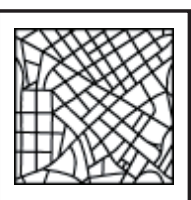

A1 Pequenos quarteirões irregulares

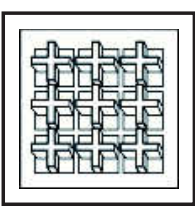

A8 Blocos abertos

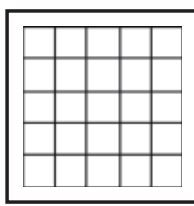

A2 Grandes quarteirões

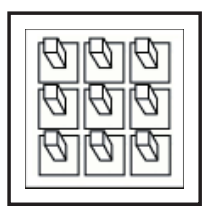

A9 Torres

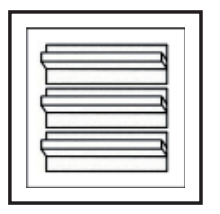

A3 Quarteirões orientados em relação ao sol

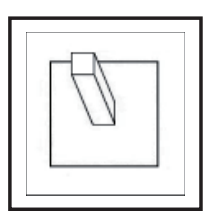

A10 Torre isolada

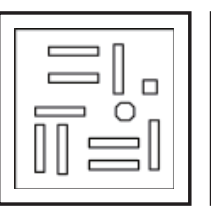

A4 Superquadras

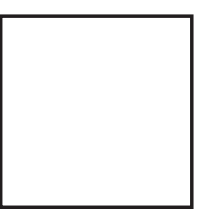

A11 Outros

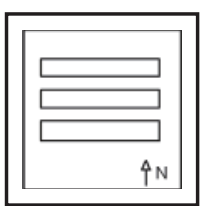

A5 Fachadas principais orientadas para Norte-Sul

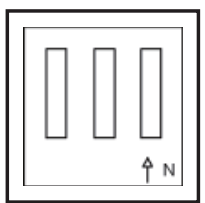

A6 Fachadas principais orientadas para LesteOeste

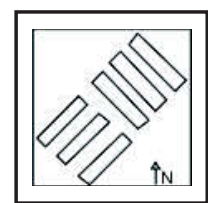

A7 Fachada principal com orientação intermediária

Figura 1: Variáveis do Parâmetro A - Desenho Urbano (Nível I - Espaço Urbano)

No caso do espaço urbano, a rua é considerada somente por sua influência na iluminação natural do edifício. As implicações diretas do desenho urbano são a quantidade de luz natural que chega no edifício, a porção do céu visível e a visão para o exterior e a ventilação do edifício (ambiente interno e externo).

Estas variáveisconfiguram diversas possibilidadesquepropiciam diferentes desempenhos do espaço urbano e do próprio edifício com relação à luz natural, desempenho térmico, ventilação natural, desempenho sonoro e eficiência energéticak. As 3 primeiras (A1, A2 e A3) têm maiores implicações na quantidade de luz natural, radiação solar e ventilação 
que atingirá o espaço urbano e os edifícios. As variáveis A5, A6 e A7 têm implicações na quantidade e qualidade de luz natural (direta ou difusa) que atinge a edificação; e as variáveis A8, A9 e A10 terão relações com a quantidade de luz natural atingindo a edificação. No entanto, todas as variáveis terão sempre relações e conseqüências no desempenho térmico e sonoro do ambiente urbano e do edifício em si.

\section{Parâmetro B - Refletância das Fachadas}

Variáveis (ver Figura 2): B1 - Alta, B2 - Média ou B3 - Baixa

\section{B - Refletância das Fachadas}

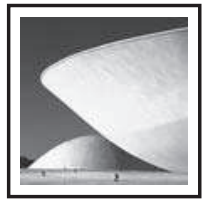

B1 Alta

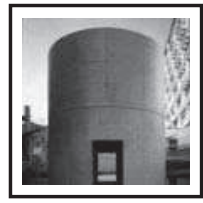

B2 Média

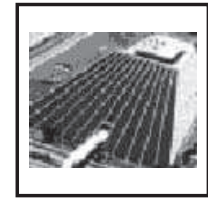

B3 Baixa

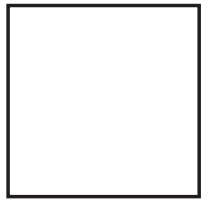

B4 Outros

Figura 2: Variáveis do Parâmetro B - Refletância das Fachadas (Nível I - Espaço Urbano) A refletância das fachadas (ou grau de reflexão, relacionado diretamente à cor) está relacionada basicamente à quantidade de luz natural refletida para o entorno, que tem conseqüências em relação ao conforto visual, térmicol, etc.

\section{Parâmetro C: Especularidade das Fachadas}

Variáveis (ver Figura 3): C1 - Alta, C2 -

\section{C - Especularidade das Fachadas}

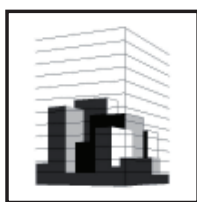

C1 Alta

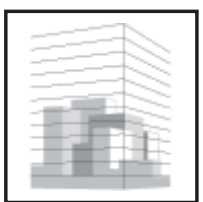

C2 Média

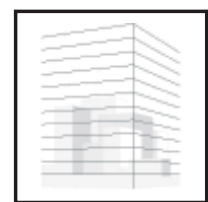

C3 Baixa

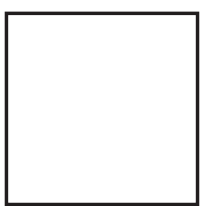

C4 Outros

Figura 3: Variáveis do Parâmetro C - Especularidade das Fachadas (Nível I - Espaço Urbano)

A especularidade das fachadas também está relacionada com a quantidade de luz refletida de maneira especular para o entorno do edifício. Caso o edifício tenha uma forma côncava ou com pátio ou átrio internos, esta variável poderá apresentar conseqüências para o próprio edifício. As implicações desta variável são principalmente a quantidade de luz natural refletida especularmente para o ambiente e a possibilidade de ofuscamento do internom.

\section{Parâmetro D: Ângulo máximo de incidência do sol na fachada do edifício}

Variáveis (ver Figura 4): D1 - Ângulo menor que $30^{\circ}, \mathrm{D} 2$ - Ângulo de $30^{\circ}$ a $60^{\circ}, \mathrm{D} 3$ Ângulo de $60^{\circ}$ a $90^{\circ}, \mathrm{D} 4$ - Ângulo de $90^{\circ}$, D5 - Outros. 


\section{D - Ângulo máximo de Incidência do Sol na Fachada do Edifício}

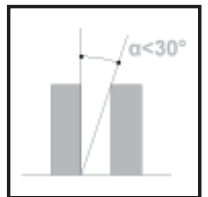

D1 Ângulo menor que $30^{\circ}$

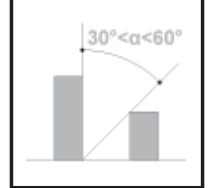

D2 Ângulo de $30^{\circ}$ a $60^{\circ}$

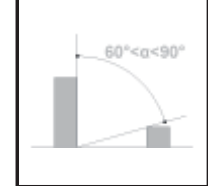

D3 Ângulo de $60^{\circ}$ a $90^{\circ}$

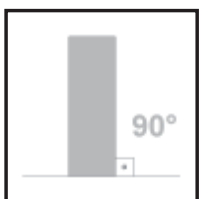

D4 Ângulo de $90^{\circ}$

Figura 4: Variáveis do Parâmetro D - Ângulo máximo de Incidência do Sol na Fachada do edifício (Nível I - Espaço Urbano)

O ângulo de incidência do sol na fachada do edifício (com relação à base do mesmo) informa sobre as condições de insolação no mesmo. As implicações destas variáveis serão principalmente a luz natural que chega aos ambientes internos e a visão do céu. Áreas urbanas com distâncias muito pequenas entre os edifícios, e consequentemente reduzidos ângulos de incidência do sol na fachada, considerando a base do edifício, proporcionam a obstrução da luz de luz natural e visão restrita do céu. ${ }^{\mathrm{n}}$

\subsection{NÍVEL II - EDIFÍCIO}

\section{Parâmetro E: Forma e Planta Baixa}

Variáveis (ver Figura 5): E1 - Edifício com planta profunda, E2 - Edifício térreo, E3 Blocos unilaterais/bilaterais, E4 - Edifício com pátio interno ou átrio, E5 - Edifício sobre pilotis, E6 - Edifício com pele dupla, E7 - Outros.

\section{E - Forma e Planta Baixa}

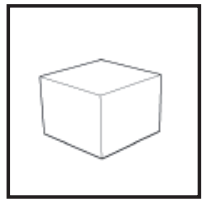

E1 Edifícios com planta profunda

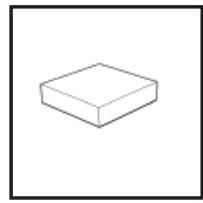

E2 Edifício térreo

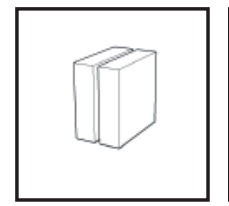

E3 Blocos unilaterais/bilaterais

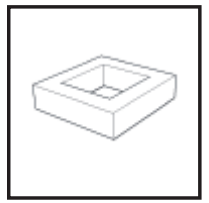

E4 Edifício com Pátio Interno ou Átrio

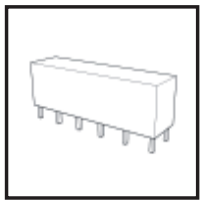

E5 Edifício sobre pilotis

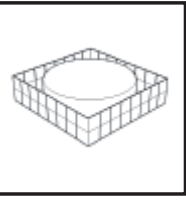

E6 Edifício com pele dupla

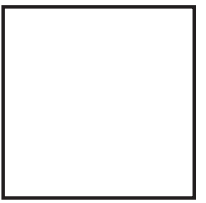

E7 Outros

Figura 5: Variáveis do Parâmetro E - Forma e Planta Baixa (Nível II - Edifício)

A forma de um edifício e sua planta têm consequiências nos aspectos de desempenho térmico e energético ${ }^{\circ}$, condicionando também a penetração de luz natural. Edifícios com planta profunda ${ }^{p}$ têm menores possibilidades de uso da luz natural nos espaços internos. No caso de edifícios térreos, esta profundidade pode ser compensada pelo uso de zenitais, e no caso de edifícios com átrio ou pátio interno, otimiza-se o uso da luz natural através do vazio interno. Edifícios unilaterais ou bilaterais ${ }^{q}$ são edifícios de forma alongada, com uma ou duas fontes de luz laterais, que garantem boa possibilidade de uso da luz natural. Os edifícios com pilotis são uma variação do edifício bilateral ou unilateral, que não influencia no uso da luz natural, mas tem conseqüências do ponto de

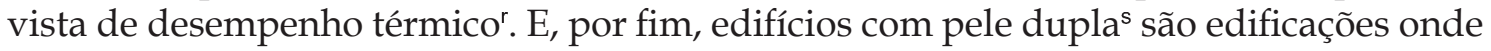
se acrescenta uma outra camada de controle à pele (ou invólucro) existente, o que irá condicionar as trocas térmicas, luminosas e energéticas e a ventilação. 


\section{Parâmetro F: Taxa de Aberturas nas Fachadas}

Variáveis (ver Figura 6): F1 - Até $25 \%$ de aberturas, F2 - Entre 25 e 50 \% de aberturas, F3 - Entre 50 e $75 \%$ de aberturas, F4 - Mais de $75 \%$ de aberturas.

F - Taxa de Aberturas nas Fachadas
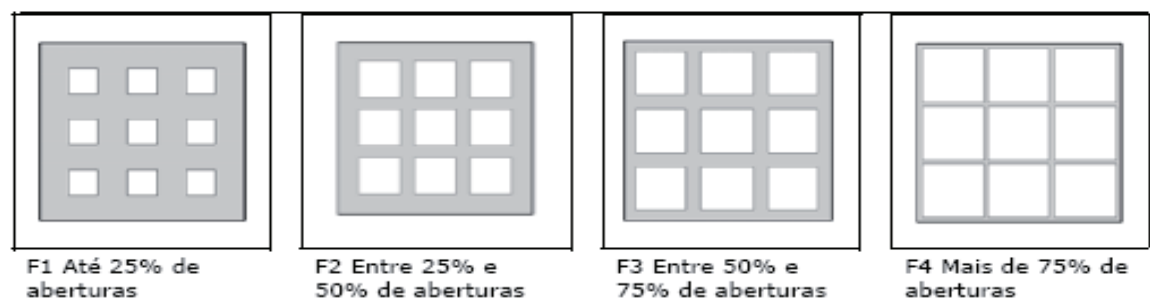

Figura 6. Variáveis do Parâmetro F - Taxa de Aberturas nas Fachadas (Nível II - Edifício)

A taxa de aberturas ${ }^{t}$ nas fachadas condiciona também as trocas térmicas, a quantidade e qualidade de luz natural, a visão para o exterior e os aspectos energéticos do edifício. Em geral, pode-se afirmar que mais de $50 \%$ de aberturas envidraçadas em fachadas pode consistir em um aspecto problemático para qualquer tipo de clima, frio ou quente (BANNISTER et al apud BRAGA, 2005).

\section{Parâmetro G: Distribuição de Aberturas nas Fachadas}

Variáveis (ver Figura 7): G1 - Fachadas uniformes, G2 - Fachadas não uniformes com relação à orientação solar, G3 - Fachadas não uniformes com relação ao espaço urbano, G4 - Outros.

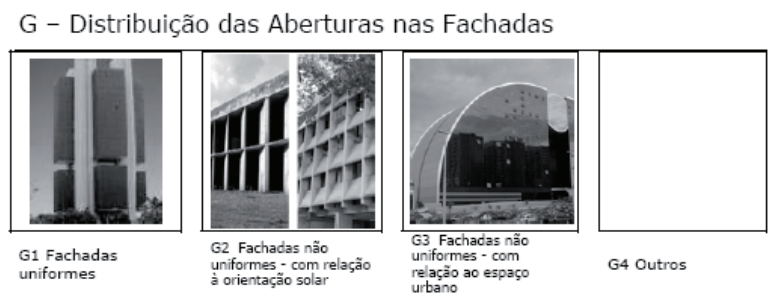

Figura 7. Variáveis do Parâmetro G - Distribuição de Aberturas nas Fachadas (Nível II - Edifício)

A distribuição de aberturas nas fachadas terá conseqüências principalmente do ponto de vista da entrada de luz (direta ou difusa), do controle solar e do controle térmico, e consequentemente no consumo energético. Fachadas uniformes ou fachadas não uniformes com relação ao espaço urbano não consideram as diferenças entre as diversas orientações (para captação do sol, da luz e dos ventos), o que acontece no caso das fachadas não uniformes com relação à orientação solar".

\section{Parâmetro H: Proteções Solares nas Fachadas}

Variáveis (ver Figura 8) : H1 - Pórticos e Varandas, H2 - Brise-soleil, H3 - Cobogós, H4 - Beirais e Marquises, H5 - Pergolados, H6 - Vegetação, H7 - Outros.

H - Proteções Solares nas Fachadas
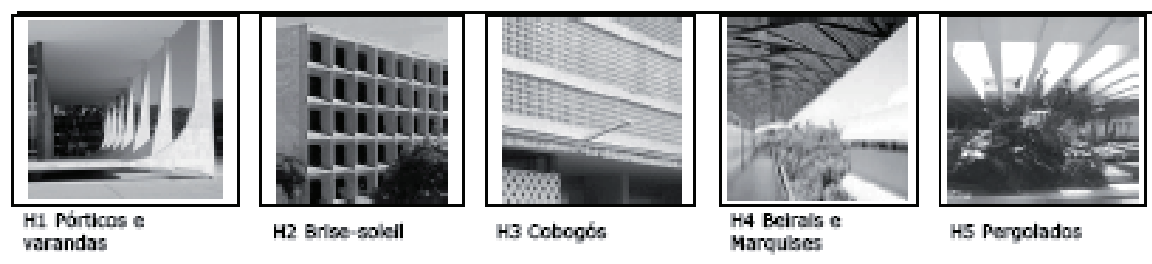

HS Pergolados

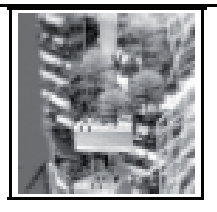

H6 Wogetactio

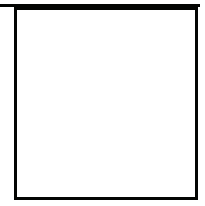

H7 Outros 
Figura 8: Variáveis do Parâmetro H - Proteções Solares nas Fachadas (Nível II - Edifício)

A presença de proteções solares nas fachadas irá condicionar a entrada de luz direta/ difusa, os ganhos térmicos e a vista para o exterior ${ }^{\mathrm{v}}$. É extremamente desejável que as proteções sejam projetadas segundo a necessidade de cada fachada.

\section{Parâmetro I: Aberturas Zenitais}

Variáveis (ver Figura 9): I1 - Clarabóia, I2 - Lanternim, I3 - Shed ou dente de serra, I4 - Zenital horizontal, I5 - Poço de luz, I6 - Não há, I7 - Outros.

I - Aberturas Zenitais

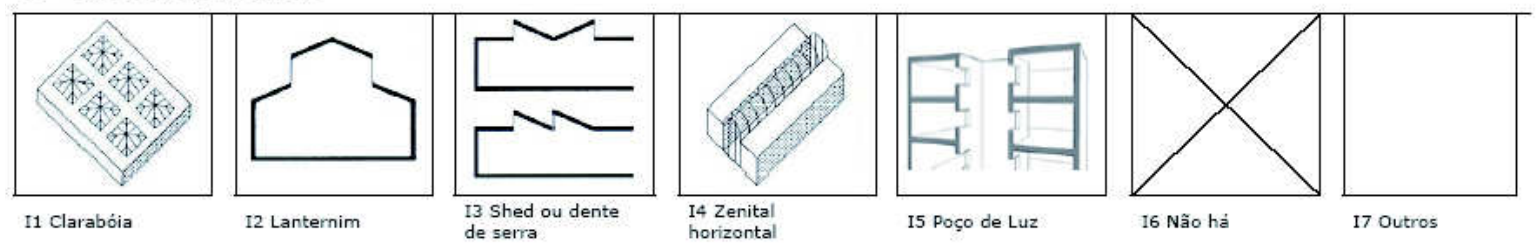

Figura 9: Variáveis do Parâmetro I - Aberturas Zenitais (Nível II - Edifício)

O tipo de aberturas zenitaisw, sua forma e inclinação irão condicionar a distribuição de luz natural, sua quantidade e qualidade (direta ou difusa) e os ganhos térmicos da edificação. De maneira geral, os zenitais com superfícies iluminantes horizontais apresentam maiores ganhos térmicos e maior possibilidade de ofuscamento por reflexão, permitindo a entrada de luz direta ${ }^{x}$. Os zenitais do tipo lanternim, shed ou dente de serra apresentam maiores vantagens do ponto de vista do controle da luz natural. ${ }^{y}$.

\section{Parâmetro J: Mecanismos de Ventilação Natural ${ }^{z}$}

Variáveis (Ver Figura 10): J1 - Cruzada, J2 - Cruzada adjacente, J3 - Efeito chaminé, J4 - Abertura única, J5 - Não há J6 - Outros.

J - Mecanismos de Ventilação Natural

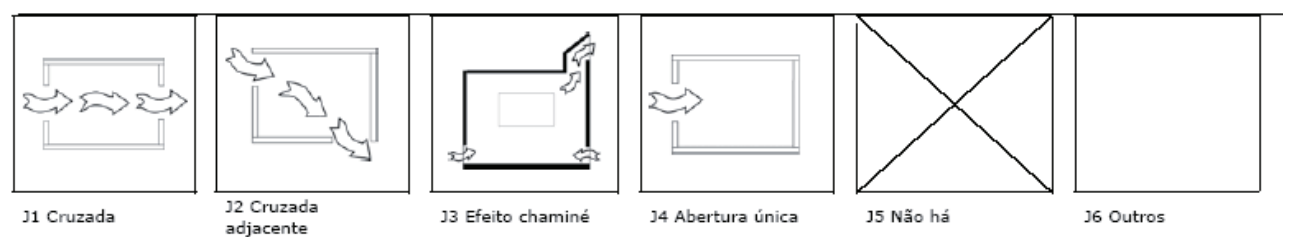

Figura 10: Variáveis do Parâmetro J - Mecanismos de Ventilação (Nível II - Edifício)

As implicações dos mecanismos de ventilação natural serão no conforto térmico, salubridade do ar e consequentemente no consumo energético para climatização. Nem sempre as aberturas para ventilação são as mesmas de iluminação, e pode ser desejável separar estas duas funções para controlar melhor o desempenho global da abertura. Toda abertura, de qualquer modo, tem conseqüências no desempenho térmico, luminoso e acústico do edifício.

NÍVEL III - AMBIENTE INTERNO

\section{Parâmetro L: Planta baixa}

Variáveis (ver Figura 11): L1 - Unilateral, L2 - Bilateral, L3 - Profunda, L4 - Outros. 


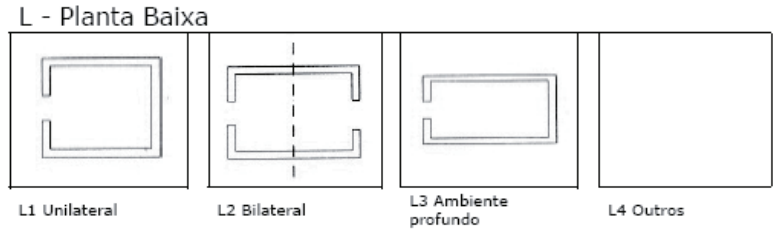

Figura 11: Variáveis do Parâmetro L - Planta Baixa (Nível III - Ambiente Interno)

Estas variáveis seguem o mesmo raciocínio do parâmetro E - Forma e Planta Baixa. Têm implicações na penetração e distribuição de luz natural, principalmente. Se forem aberturas também para ventilação, terão influência no desempenho e conforto térmico do ambiente, e gasto energético para climatização.

\section{Parâmetro M: Posição do Coletor de Luz}

Variáveis (ver Figura 12): M1 - No centro do plano lateral, M2 - No centro do plano zenital, M3 - Entre planos, M4 - Ao longo do canto entre planos, M5 - Parede aberta, M6 - Outros.

M - Posição do Coletor de Luz

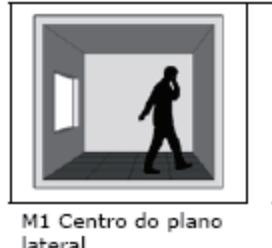

ateral

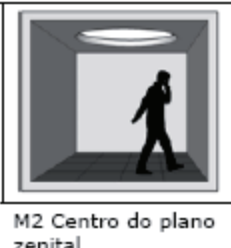

zenital

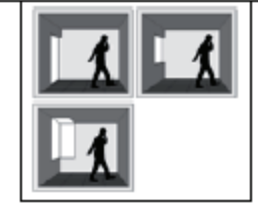

M3 Entre planos

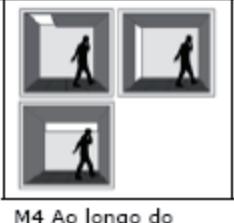

M4 Ao longo do

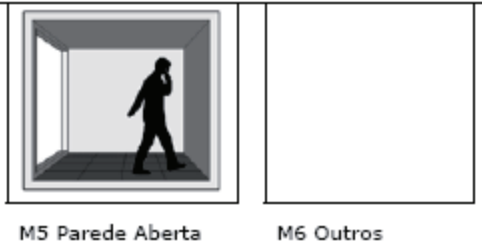

M6 Outros

Figura 12: Variáveis do Parâmetro M - Posição do Coletor de Luz (Nível III- Ambiente Interno) A posição do coletor de luz (lateral ou zenital) terá influência na quantidade e distribuição de luz natural, na possibilidade de ofuscamento, visão para o exterior e ganhos térmicos e ventilação, caso sejam também aberturas para ventilação. De forma geral, janelas laterais mais altas garantem maior profundidade de penetração da luz natural ${ }^{\text {aa }}$. Por outro lado, é importante considerar a possibilidade de vista para o exterior, que as janelas altas não permitem $^{\text {ab }}$, e também possíveis problemas de ofuscamento devido à visão da abóbada celeste.

\section{Parâmetro N: Dimensão do coletor de luz}

Variáveis (ver Figura 13): M1 - Abertura lateral de até 15 \%, M2 - Abertura lateral entre 15 e $30 \%$, M3 - Abertura lateral maior que $30 \%$, M4 - Abertura zenital de até $15 \%$, M5 - Abertura zenital entre 15 e $30 \%$, M6 - Abertura zenital maior que $30 \%$.

$\mathrm{N}$ - Dimensão do Coletor de Luz

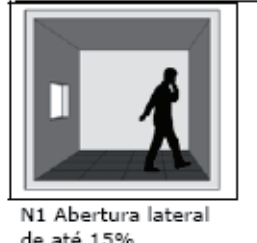

de até $15 \%$

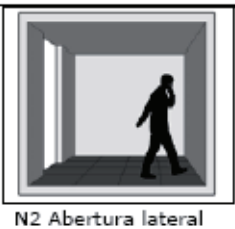

de $15 \%$ a $30 \%$

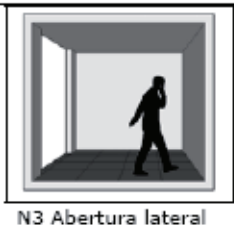

de acima de $30 \%$

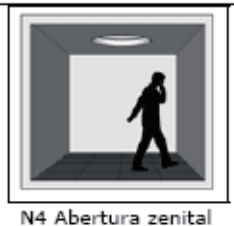

de até $15 \%$

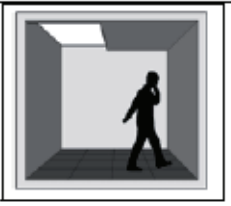

N5 abertura zenital de $15 \%$ a $30 \%$

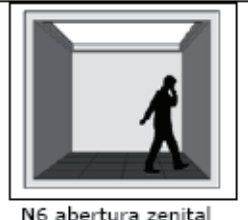

N6 abertura zenital

Figura 13: Variáveis do Parâmetro N - Dimensão do Coletor de Luz (Nível III - Ambiente Interno) A dimensão do coletor de luz irá influenciar principalmente nos ganhos térmicos e luminosos, podendo gerar problemas de ofuscamento e desconforto térmico. A dimensão refere-se à porcentagem de área de abertura (envidraçada ou não) com relação à área opaca.

\section{Parâmetro O: Forma do coletor de luz}


Variáveis (ver Figura 14): O1 - Janela intermediária, O2 - Janela horizontal, O3 - Janela vertical, O4 - Cortina de vidro, O5 - Abertura zenital horizontal, O6 - Abertura zenital vertical (tipo shed), O7 - Teto envidraçado, O8 - Outros.

O - Forma do Coletor de Luz
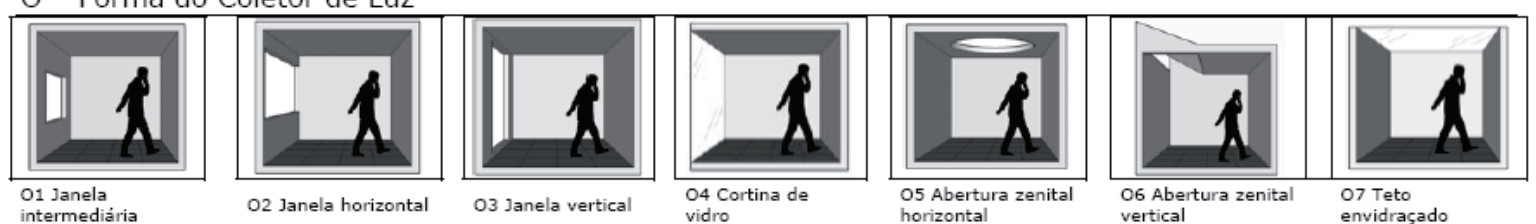

Figura 14: Variáveis do Parâmetro O - Forma de Coletor de Luz (Nível III - Ambiente Interno) A forma do coletor de luz irá influenciar principalmente na distribuição de luz natural dentro do ambiente, na possibilidade de ofuscamento, na visão para o exterior e nos ganhos térmicos ${ }^{\mathrm{ac}}$.

\section{Parâmetro P: Controle da entrada de luz}

Variáveis (ver Figura 15): P1 - Peitoril, P2 - Prateleiras de luz, P3 - Beirais ou toldos, P4 - Brises, P5 - Cobogós, P6 - Cortinas, películas ou vidros especiais, P7 - Outros.

P - Controle de Entrada de Luz

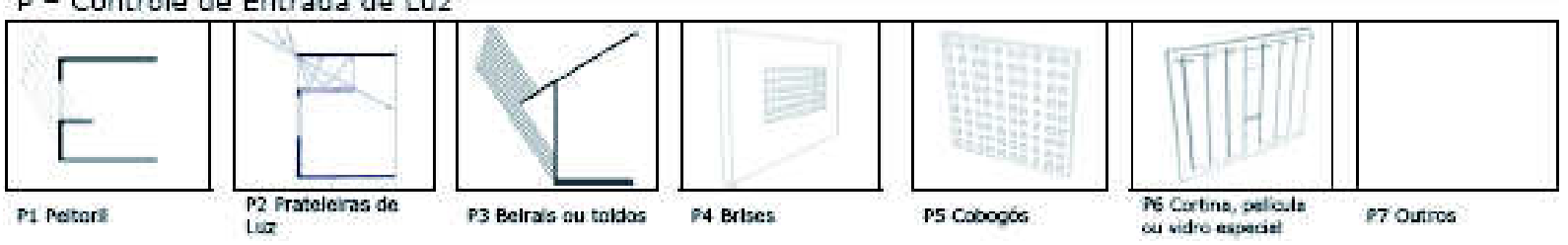

Figura 15: Variáveis do Parâmetro P - Controle da Entrada de Luz (Nível III - Ambiente Interno)

O controle da entrada de luz pode ser realizado através de inúmeros aparatos ${ }^{\text {ad }}$, incluindo o próprio peitoril da janela, as prateleiras de luz, beirais, brises, etc. O uso destes elementos irá influenciar na quantidade e qualidade da luz natural, na carga térmica e na ventilação do ambiente. Esta proteção terá maior efeito com relação ao calor se for externa, sendo que os elementos internos como cortinas têm maior efeito de controle da luminosidade. As películas ou vidros de controle solar devem ser especificados como complemento da proteção externa ${ }^{\text {ae }}$.

\section{Parâmetro Q: Controle da ventilação natural ${ }^{\text {af }}$}

Variáveis (ver Figura 16): Q1 - Janela de correr, Q2 - Janela máximo ar ou basculante, Q3 - Janela pivotante, Q4 - Janela guilhotina, Q5 - Abertura com lamelas, Q6 - Abertura no teto, Q7 Outros

Q - Controle da Ventilação Natural
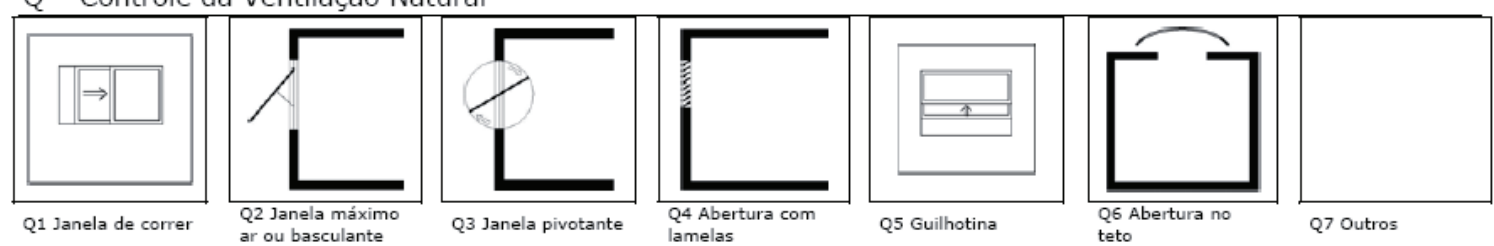

Figura 16: Variáveis do Parâmetro Q - Controle da Ventilação Natural (Nível III - Ambiente Interno)

O tipo de abertura (considerando-se a área de abertura e o funcionamento da esquadria) influenciará enormemente no fluxo de ventilação natural resultante, e em seu controle. É importante que a abertura propicie o fluxo adequado e permita o controle da ventilação, dependendo das necessidades do clima local. ${ }^{\text {ag }}$

\section{Parâmetro R: Controle e integração da iluminação artificial ${ }^{\text {ah }}$}


Variáveis (ver Figura 17): R1 - On/off, R2 - On/off com sensor, R3 - Dimming, R4 Dimming com sensor, R5 - Sensor de presença ou temporizador, R6 - Outros.

$\mathrm{R}$ - Controle e Integração da Iluminação Artificial

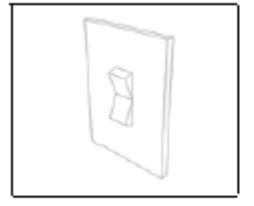

R1 On/off manual

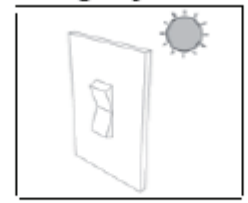

R2 On/off com

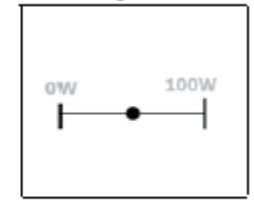

R3 Dimming

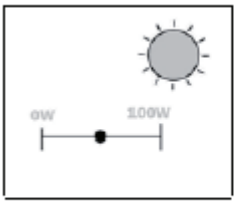

R4 Dimming com sensor

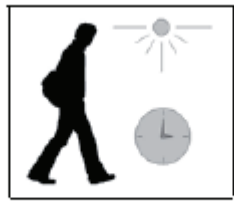

R5 Sensor de presença ou

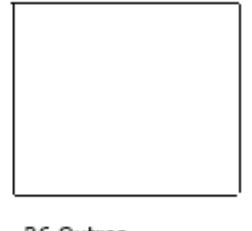

R6 Outros

Figura 17: Variáveis do Parâmetro R - Taxa de Aberturas nas Fachadas (Nível III - Ambiente Interno) Este parâmetro avalia um aspecto importantíssimo para a eficiência energética do edifício: o controle e integração da iluminação artificial com a luz natural. De fato, se não houver esta integração, o ambiente terá maior conforto luminoso e qualidade ambiental através do uso da luz natural, mas não necessariamente maior eficiência energética. O bom uso dos controles e da integração da luz artificial poderá proporcionar maior conforto luminoso, redução de contrastes e ofuscamentos e economia energéticaai.

Apresenta-se a seguir a legenda completa do Diagrama Morfológico ${ }^{\text {aj }}$ (ver Figuras 18, 19 e 20) e em seguida considerações sobre os procedimentos para sua utilização para análise de um edifício existente ou no processo projetual. 


\section{A - Desenho Urbano}

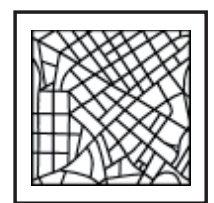

A1 Pequenos quarteirões

irregulares

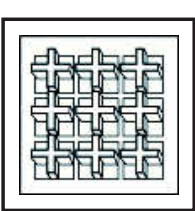

A8 Blocos abertos

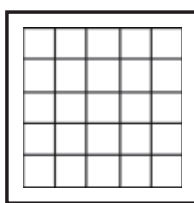

A2 Grandes quarteirões

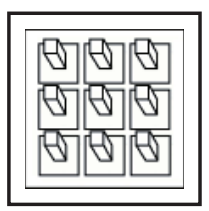

A9 Torres

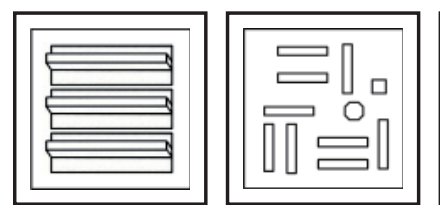

A3 Quarteirões A4 Superquaorientados em dras relação ao sol

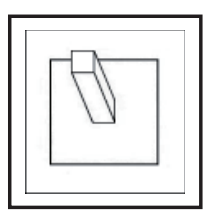

A10 Torre isolada

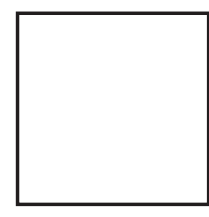

A11 Outros

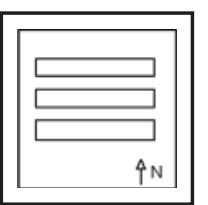

A5 Fachadas principais orientadas para Norte-Sul

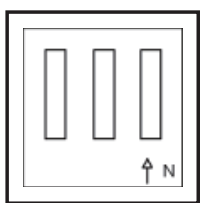

A6 Fachadas principais orientadas para LesteOeste

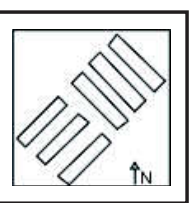

A7 Fachada principal com orientação intermediária

\section{B - Refletância das Fachadas}

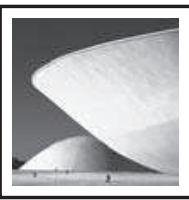

B1 Alta

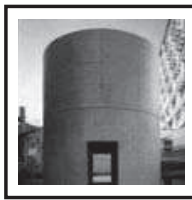

B2 Média

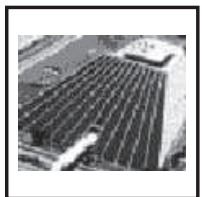

B3 Baixa

\section{C - Especularidade das Fachadas}

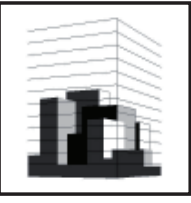

C1 Alta

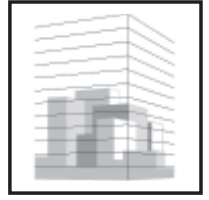

C2 Média

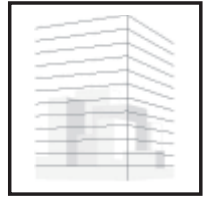

C3 Baixa

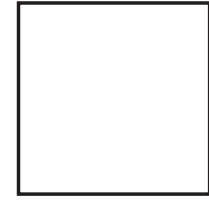

C4 Outros

D - Ângulo máximo de Incidência do Sol na Fachada do Edifício

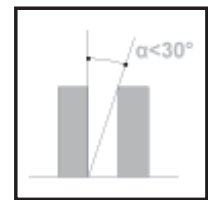

D1 Ângulo menor que $30^{\circ}$

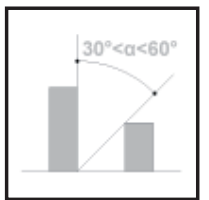

D2 Ângulo de $30^{\circ}$ a $60^{\circ}$

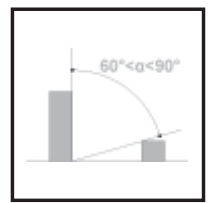

D3 Ângulo de $60^{\circ}$ a $90^{\circ}$

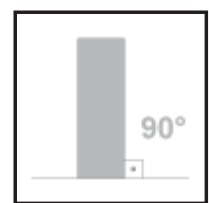

D4 Ângulo de $90^{\circ}$

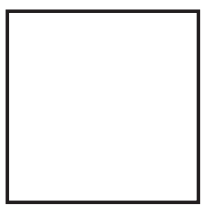

D5 Outros 
Parâmetros do nível II - Edifício

E - Forma e Planta Baixa
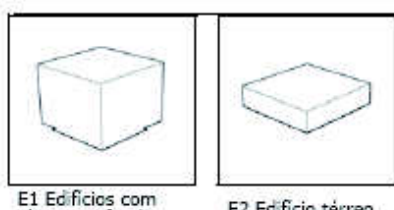

E2 Ed ficio térreo

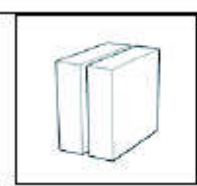

E3 Elocos
unilaterais/bilaterais

ais

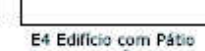

E4 Edificio com Pátic

F - Taxa de Aberturas nas Fachadas

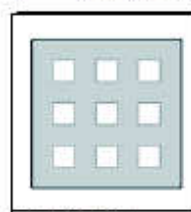

F1 Até $25 \%$ de

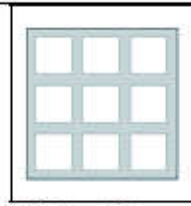

F3 Entre $50 \%$ e
$75 \%$ de aberturas

F2 Entre $25 \%$ e

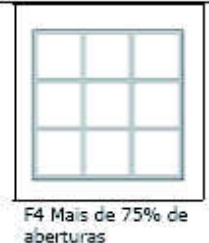

aberturas

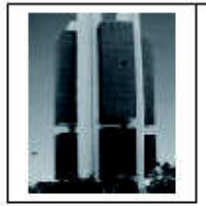

G1 Fachadas

uniformes

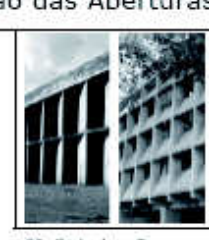

G2 Fachadas n⿳亠丷厂

G2 Fachadas nas
uniformes - com relaş;
i orientaça solar

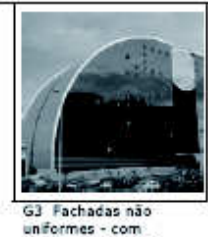

G3 Fachadas não
unformes - com

informes - com
relsçao aso espaç
urtano

H - Proteções Solares nas Fachadas

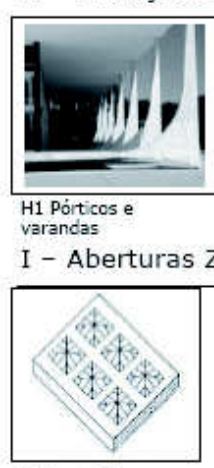

I1 Clarabóia

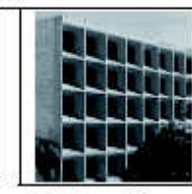

H2 Brise-solel

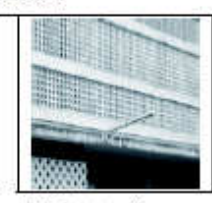

H3 Combogós

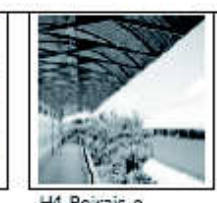

H4 Beirais e Hu Beirais e
Marquises

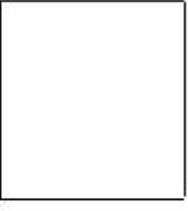

G4 Outros

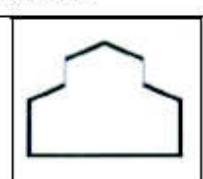

I2 Lanternim

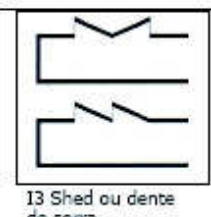

13 Shed
de serva

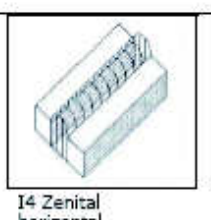

horizontal

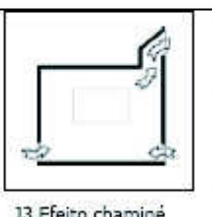

13 Efeito chaminé

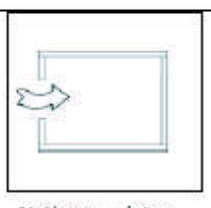

24 Abertura única

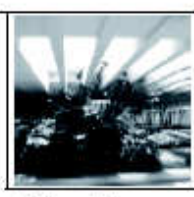

H5 Pergolados

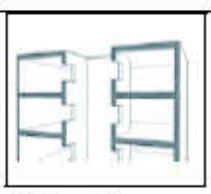

15 Poço de Luz

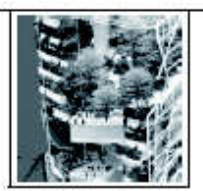

H6 Vegetação

H7 Outros

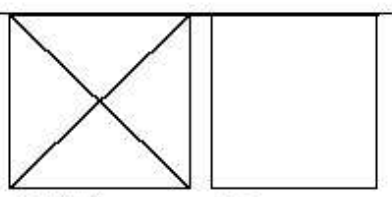

16 Não há

17 Outros

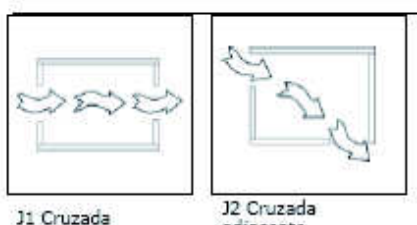

11 Cruzada adjacente
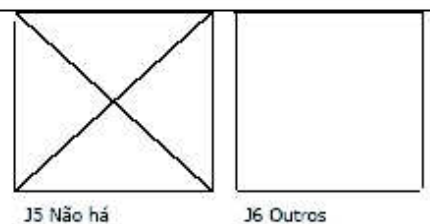

36 Outros 


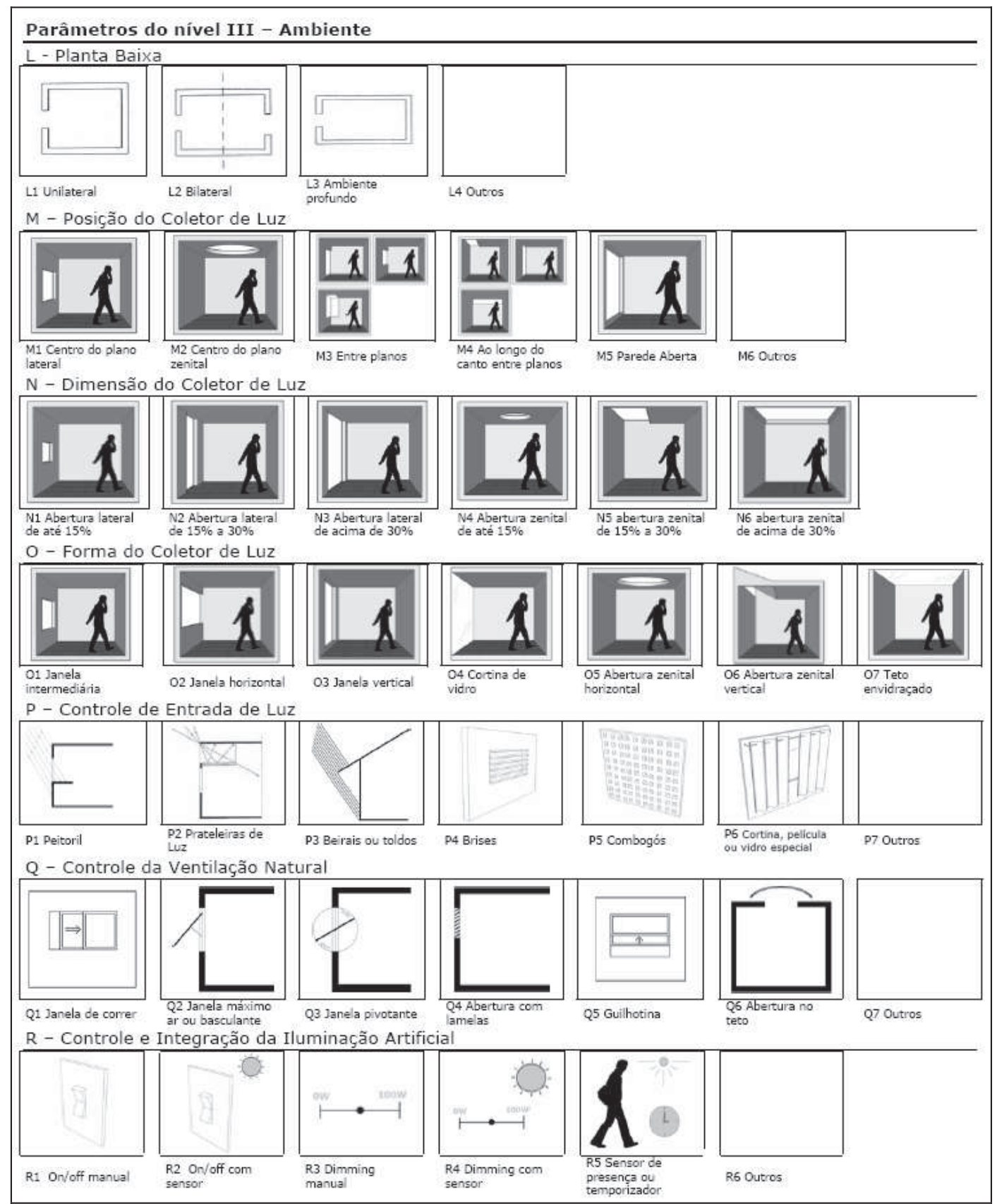

Figura 20: Diagrama Morfológico - Legenda Parâmetros do Nível III - Ambiente Interno 


\section{DIAGRAMA MORFOLÓGICO: COMPILAÇÃO PARA ANÁLISE E PROJETO}

O uso do Diagrama Morfológico para análise de projetos existentes ou como instrumento do processo projetual prevê a compilação dos dados em uma seqüência que parte do maior (o Espaço Urbano), passando pelo Edifício e chegando ao Ambiente (que pode ser um único ambiente do edifício, ou ambientes representativos do edifício, que servem para caracterizálo) ${ }^{\text {ak }}$. O preenchimento inicia-se colocando dados básicos da edificação, como Tipologia, Localização (cidade, latitude, longitude, altitude), Data de Construção, Arquiteto. Seguem-se dados sobre o Clima Local (pequena descrição elencando tipo de clima, temperaturas - média anual e médias mínimas e máximas - radiação solar, duração de insolação, ventos, chuvas, etc), e a carta solar local. A seguir uma planta mostrando a implantação do edifício ou foto aérea mostrando a inserção do projeto no contexto urbano; e os Parâmetros e Variáveis de cada Nível (Urbano, Edifício e Ambiente), ilustrados com fotos e desenhos significativos dos aspectos que se deseja evidenciaral.

No caso da avaliação de um projeto, utiliza-se marcar em cor os aspectos que são percebidos como pontos a serem ainda "otimizados" no projeto ou no edifício existente, ou seja, aspectos que, na opinião do avaliador ou projetista, ainda necessitam de ajustes por apresentarem problemas (no desempenho da luz natural, térmico, sonoro ou de eficiência energética). A visualização das marcações em fundo diferenciado (cinza ou outra cor) permite uma leitura rápida dos pontos a serem otimizados.

É importante lembrar que as avaliações efetuadas baseiam-se no conhecimento das estratégias de projeto adequadas ao clima local; as primeiras informações preenchidas no Diagrama referem-se ao clima da localidade, percurso solar, etc, e isto será a base para avaliação das soluções projetuais. A mesma solução projetual para uso da luz natural pode ser adequada em um clima temperado, mas considerada problemática quando utilizada em um edifício em clima tropical.

De maneira geral, o uso do Diagrama deve ser feito para a análise e a catalogação de projetos considerados exemplares na utilização da luz natural e na adequação ao contexto climático. Isto possibilitará a criação de um repertório a ser armazenado. $\mathrm{Ou}$, como dito anteriormente, para avaliar projetos em andamento (pode-se utilizar o Diagrama na fase de anteprojeto, por exemplo, parachecarassoluçõesjáadotadas e os possíveis problemas); posteriormente, pode-se aplicar novamente o Diagrama na fase de projeto executivo, quando já há mais detalhes. No entanto, mesmo na catalogação e análise de um projeto considerado inicialmente exemplar, podem emergir aspectos passíveis de otimização, que ficam mais evidentes ao examinalo atentamente com um instrumento de análise mais detalhado.

\section{CONSIDERAÇÕES FINAIS}

As exigências ambientais para o projeto arquitetônico vem crescendo de maneira progressiva. Neste sentido, o papel da luz natural como critério de projeto para maior qualidade ambiental (entendida como conforto ambiental e eficiência energética, principalmente) é crucial. Por outro lado, é fato que o processo de projeto apresenta uma série de incertezas que podem dificultar a aplicação dos conceitos no projeto. Neste sentido, o Diagrama Morfológico é proposto como instrumento para análise e auxílio na concepção de projetos, levando em consideração os aspectos e as relações entre o Espaço Urbano, Edifício e Ambiente com a luz natural e suas conseqüências ambientais ligadas ao conforto ambiental e eficiência energética do espaço construído.

A proposta é que o Diagrama seja utilizado tanto para análise de edifícios considerados exemplares do ponto de vista da luz natural, quanto para auxílio no processo de projeto, nas fases iniciais e finais do projeto.

Uma possível evolução deste instrumento poderá relacionar e criar escalas de valores, 
tentando relacionar o uso de determinadas estratégias de projeto como sendo mais adequadas segundo o tipo de clima. Desta maneira, poder-se-ia criar uma escala de valores que daria indicações ainda mais precisas aos projetistas quanto ao acerto de suas soluções para aquele determinado contexto.

Oinstrumento podecolaborar para criação de repertório de projeto, além de apoiar o próprio processo projetual, auxiliando no desenvolvimento do senso crítico com relação ao uso da luz natural, fundamental para o projetista, a qualidade ambiental e sustentabilidade de seus projetos.

\section{REFERÊNCIAS}

ABNT - ASSOCIAÇÃO BRASILEIRA DE NORMAS TÉCNICAS, Rio de Janeiro. NBR 15215-2: Iluminação natural - Parte 1. Rio de Janeiro: ABNT, 2005.

ABNT - ASSOCIAÇÃO BRASILEIRA DE NORMAS TÉCNICAS, NBR ISO 14050 - Gestão Ambiental - Vocabulário. Rio de Janeiro: ABNT, 2004.

AMORIM, C.N.D. Iluminação Natural e Eficiência Energética - Parte I: Estratégias de Projeto para uma arquitetura sustentável. Brasília: Periódico eletrônico em Arquitetura e Urbanismo Paranoá,Vol.4, 2002. Disponível em http://www.unb.br/fau/pos_ graduacao/paranoa/paranoa.htm.

AMORIM, C. N. D. Sustentabilidade, qualidade ambiental e iluminação natural no espaço construído: conceitos básicos - Revista Paranoá. Brasília: PPG/FAU, Universidade de Brasília, 2007.

AMORIM, C. N. D. Recursos Físicos para Luz Natural. Apostila da disciplina do curso Projetos Luminotécnicos - Lighting Design. Universidade Castelo Branco, Rio de Janeiro, 2006.

AMORIM, C. N. D. Illuminazione Naturale, Comfort Visivo ed Efficienza Energetica in Edifici Commerciali: Proposte Progettuali e Tecnologiche in contesto di clima Tropicale. 2001. Tese de Doutorado. Università degli Studi di
Roma “La Sapienza” (desenvolvida no Politecnico di Milano), 2001.

BAKER, N. \& STEEMERS, K. Daylight design of buildings. London: James and James Editors, 1998.

BAKER, N.;FANCHIOTTI, A.;STEEMERS, Koen. Daylighting in architecture: A European Reference Book. Londres: James and James Editors, 1993.

BELL, J.; BURT, W. Designing buildings for daylight. London: BRE, CIBSE, 1995.

BITTENCOURT, Leonardo. Uso das cartas solares - diretrizes para arquitetos. 3 ed. rev. Maceió: EdUFAL. Universidade Federal de Alagoas, 2000.

BITTENCOURT, Leonardo. Ventilação natural. Ed. Maceió: UFAL, 2006.

BRAGA, DarjaKos. Arquiteturaresidencial das superquadras do Plano Piloto de Brasília: aspectos de conforto térmico. Dissertação (Mestrado em Arquitetura e Urbanismo). Programa de Pós-Graduação em Arquitetura eUrbanismo, Universidade de Brasília, 2005.

CORBELLA, Oscar; YANNAS, Simos. Em busca de uma arquitetura sustentável para os trópicos. Rio de janeiro: Ed. Revan, 2003.

FONTOYNONT, M.(Ed.). Daylighting performance in buildings. London: James and James,1998.

GARROCHO, J. S. Luz Natural e projeto de Arquitetura: estratégias para iluminação zenital em centros de compras. Dissertação (Mestrado em Arquitetura e Urbanismo). Programa de Pós-Graduação em Arquitetura eUrbanismo, Universidade de Brasília, 2005.

FROTA, Anésia; SCHIFFER, Sueli R. Manual de conforto térmico. São Paulo: Studio Nobel, 1999.

IEA -International Energy Agency. Daylighting Design Tools. Results of Subtask C. IEA SHC TASK 21 / IEA ECBCS ANNEX 29: Daylight in Buildings, 1999.

IEA - International Energy Agency. Daylight in buildings: a source book on 
daylighting systems and components. A report of IEA Task 21/ Ecbcs, Annex 29. 2000.

LAM, W. Sunlighting as a formgiver for architecture. New York: Van Nostrand Reinhold Company, 1986.

LAMBERTS, R.; DUTRA, L. e PEREIRA, F. Eficiência energética na arquitetura. UFSC/Procel/ Eletrobrás, 1998.

MOORE, F. Concept and practice of architectural daylighting. New York : Van Nostrand Reinhold Company, 1985.

OLIVEIRA, Paulo Marcos. O céu estrelado ou firmamento: uma ambiência luminosa de referência. Cadernos Eletrônicos da Pós, FAU-UnB, 2000.

OLGYAY, V. Arquitectura y clima -Manual de diseño bioclimático para arquitectos y urbanistas. Barcelona: Gustavo Gilli. 1998

SERRA, R. F. \& COCH, H. R. Arquitectura y energia natural. Barcelona: Edicions UPC. 1991.

ROBBINS, C. Daylighting. Design and analyses. New York : Van Nostrand Reinhold C, 1986.

ROGORA, A. Luce naturale e progetto. Rimini: Maggioli Editori, 1997.

ROMERO, Marta. Princípios bioclimáticos para o desenho urbano. São Paulo: Projeto, 1988.

SILVA, Joene Saibrosa. A eficiência do brise-soleil em edifícios públicos de escritórios: estudo de casos no Plano Piloto de Brasilia. Dissertação (Mestrado em Arquitetura e Urbanismo). Programa de Pós-Graduação em Arquitetura e Urbanismo, Universidade de Brasília, 2007.

TORRICELLI, M.C; SALA, M.; SECCHI, S. La luce del giorno. Tecnologie e strumenti per la progettazione. Firenze: Alinea Editrice, 1996.

VIANNA, Nelson Solano e GONÇALVES, Joana Carla Soares. Iluminação e arquitetura. São Paulo: Geros S/C Ltda, 2001.

\section{Agradecimentos:}

Ao $\mathrm{CNPq}$, pelos financiamentos para esta pesquisa através do programa CT-Energ e Edital Universal e ao PROCEL, através de bolsa para aluno de Iniciação Científica.

\section{NOTAS}

a A ISO 14050 define meio ambiente como a "circunvizinhança em que uma organização opera, incluindo ar, água, solo, recursos naturais, flora, fauna, seres humanos e suas inter-relações". O desempenho ambiental de um espaço construído (edificação ou área urbana) é, portanto, o "resultado da gestão desta organização (o espaço construído) sobre seus aspectos ambientais".

b A qualidade ambiental, segundo Piardi, apud AMORIM, 2002 considera as relações físicas, materiais e energéticas entre a construção e o ambiente que a circunda, relacionando parâmetros como o conforto ambiental interno, o consumo energético, a segurança, o impacto ambiental da construção e do uso do edifício, entre outros. Os aspectos da qualidade ambiental abordados no âmbito deste artigo referem-se principalmente à iluminação natural e itens a esta relacionados, como por exemplo, conforto ambiental e uso de energia.

c Entende-se por projetista, para os fins deste artigo, todos os envolvidos no processo de projeto arquitetônico e complementares: arquitetos, engenheiros, luminotécnicos, etc. O conceito mais amplo subtende que o processo de projeto seja executado de maneira integrada, abarcando todos os profissionais em todas as fases, permitindo o compartilhamento na tomada de decisões. Para o projeto que visa a uma maior adequação ambiental, este seria o processo ideal, contemplando a multidisciplinaridade.

d Para estefim, istoé, adaptar uma edificação/ construção que não mais se adequa às exigências da modernidade, existem os processos de reabilitação, requalificação, retrofit ou reestruturação de edifícios ou áreas urbanas. Estes processos contemplam mudanças de uso do espaço, atendimento a novas normas e exigências legais, assim como de resolução de problemas ligados ao envelhecimento das estruturas, instalações e materiais de construção.

e TORRICELLI, M. C; SALA, M.; SECCHI, S. La luce del giorno. Tecnologie e strumenti per la progettazione. Firenze: Alinea Editrice, 1996. p. 49.

f A questão ambiental neste artigo diz respeito especialmente a eficiência energética e conforto ambiental no espaço construído. Com relação a isto, o Brasil conta ainda com poucas normas de eficiência energética em edificações, tendo iniciado há poucos anos a construção de uma estrutura normativa . Desta maneira, é importante consolidar certos conceitos e tornar claro aos projetistas como utiliza-los.

g Segundo BAKER et al , uma Gramática Tipológica Arquitetônica é um conjunto de regras 
de composição, que gera um repertório de tipos arquitetônicos.

h "Em tempos de desafios impostos pela ecologia e pela própria complexidade das cidades, a visão integrada é uma estratégia fundamental. Precisamos ver o urbanismo como arquitetura numa escala maior, o paisagismo como um urbanismo permeável, a arquitetura como um urbanismo especializado - um justificando o outro como forma de imbricá-los de maneira indissociável." (Teixeira, Carlos M. "Outros olhares sobre a cidade. Urbanismo arquitetônico, paisagismo urbano, arquitetura paisagística" Revista AU abril 2007). Embora o Diagrama não envolva diretamente o paisagismo, este conceito retrata bem a idéia do mesmo.

i Esta variável foi proposta especificamente pensando no espaço urbano do Plano Piloto de Brasília, sendo peculiar a esta cidade. A superquadra é configurada num arranjo espacial típico, que tem certas conseqüências similares às das variáveis $\mathrm{A} 5 \mathrm{e}$ A6 combinadas.

j A maioria dos Parâmetros inclui a variável Outros, para permitir a inclusão de situações não contempladas no Diagrama.

k A este respeito, consultar dentre outros Romero (1986) e Serra e Coch (1995).

1 Ver Frota e Schiffer (1998) e, Corbella e Yannas (2003).

m Ver Baker et al (1994).

n A visão do céu é um importante aspecto da luz natural, assim como a vista para o exterior, pois contribui para a percepção do passar do tempo e das condições metereológicas, itens importantes para garantir a qualidade ambiental (BELL e BURTON apud AMORIM, 2006).

o A este respeito, ver também Serra e Koch (1995) e Oliveira (1998).

$\mathrm{p} \quad$ Considerando que como regra geral a luz natural pode penetrar até 2,5 vezes a altura máxima da janela (VIANNA e GONÇALVES, 2003) no caso de iluminação lateral, a planta profunda seria aquela cuja profundidade supera esta distância.

q Entende-se por edifício unilateral o que tem somente uma entrada para luz natural e bilateral o que tem duas entradas para luz natural, em lados opostos. Isto tem também conseqüências na possibilidade de ventilação natural do edifício.

r O pilotis aumenta a superfície de contato da forma, pois estando a forma suspensa e não assentada, diminui a compacidade, propiciando maiores trocas térmicas. A respeito da forma, ver Olgyay (1962), Serra e Coch (1995).

s Ou "double skin", que significa uma segunda pele acrescentada ao invólucro original do edifício.

t Caso sejam aberturas também para ventilação, terão todas estas conseqüências; caso contrário, sua influência será somente na entrada de luz direta ou difusa.

u Este aspecto é extremamente desejável, pois permite que o edifício adapte-se às diversas condições conforme a orientação. Encontram-se, no entanto, poucos edifícios são projetados desta forma.

V Para uma classificação e descrição dos vários tipos de proteções solares, consultar Baker et al (1993).

w Os tipos de aberturas zenitais aqui apresentados seguem a nomenclatura apresentada na Norma NBR 15215-2 parte 1, "Iluminação natural - parte 1: Conceitos básicos e definições."

$\mathrm{x} \quad$ Em climas quentes, este é um aspecto que irá influenciar negativamente o consumo de energia para climatização. Recomenda-se que neste caso, a superfície iluminante tenha no máximo $10 \%$ da área do piso a ser iluminado (VIANNA e GONÇALVES, 2001, p. 180). Os zenitais horizontais também apresentam maiores dificuldades de manutenção e proteção solar.

y $\quad$ Em latitudes de $24^{\circ}$ a $32^{\circ} \mathrm{S}$ recomendase que as superfícies verticais iluminantes estejam voltadas para sul, de forma a receber maiores quantidades de luz difusa durante todo o ano (VIANNA e GONÇALVES, 2001, p. 177). A respeito de projeto de zenitais, consultar também Robbins (1986).

z Variável não existente no Diagrama original, tendo sido acrescentada para avaliar a possibilidade de uso da ventilação natural no edifício.

aa A este respeito consultar Lam (1986),

Robbins (1986), Baker et al (1993) e Vianna e

Gonçalves (2000).

ab Também as questões de privacidade do usuário devem ser contempladas, ao se posicionar um coletor de luz, principalmente lateral.

ac Em todos estes casos, também no fluxo de ventilação, caso sejam aberturas também para ventilação.

ad Estes devem ser especificados e projetados segundo a quantidade de radiação solar, luz natural difusa e/ou direta a ser controlada. A este respeito ver Robbins (1986), Lam (1986), Baker et al (1993) e Bittencourt (2000).

ae Vianna e Gonçalves (2000) apresentam um elenco de vidros com recomendações para escolha segundo as necessidades de cada situação.

af Variável não existente originalmente, tendo sido incluída por representar importante estratégia de climatização passiva em climas tropicais.

ag Neste caso, é importante que o projetista faça, através de cálculos simplificados, uma previsão do fluxo de ventilação que poderá obter com aquele tipo de abertura (BITTENCOURT, 2006; FROTA e SCHIFFER, 1998).

ah Variável não existente originalmente, acrescentada pela sua importância na eficiência energética do edifício.

ai Ver IEA (1999) e, Bell e Burt (1995).

aj A formatação final da legenda do Diagrama Morfológico e todos os ícones foram desenhados por Eduardo Cademartori, bolsista de Iniciação Científica do Programa de Eficiência Energética do PROCEL/Eletrobrás. 
ak Sobre ambientes representativos, seguese o mesmo raciocínio utilizado para o processo de simulação computacional: o ambiente representativo é um ou mais espaços que representam um padrão de uso, ocupação e condição ambiental em um edifício. Por exemplo, em uma tipologia escolar, avaliar duas salas de aulas situadas em fachadas opostas pode ser suficientemente representativo para caracterizar o edifício.

al É importante lembrar que os desenhos (plantas, cortes, fachadas, detalhes) e fotos devem ilustrar os aspectos que se deseja evidenciar no projeto, positivos ou negativos. De preferência, ilustrar os aspectos positivos para que estes auxiliem na criação de um repertório projetual adequado. 